\title{
Possibilidades e limites da Justiça Restaurativa nas escolas públicas
}

\section{Possibilities and limits of Restorative Justice in public schools}

\author{
Arthemis Nuamma Nunes de Almeida ${ }^{1}$ \\ llana Lemos de Paiva ${ }^{2}$ \\ Ana Ludmila Freire Costa ${ }^{3}$
}

\begin{abstract}
Resumo: A violência nas escolas é uma realidade em todo o mundo, envolvendo várias modalidades e protagonistas. Nesse sentido, a Justiça Restaurativa (JR) nas escolas pretende alcançar o entendimento entre os envolvidos para que participem de sua resolutividade. No Brasil, algumas experiências pressupõem a instrumentalização dos atores escolares. Assim, objetiva-se analisar as possibilidades e os limites da Justiça Restaurativa nas escolas em uma cidade do nordeste do Brasil. Para tanto, foram realizadas 12 entrevistas semiestruturadas com representantes das escolas onde a prática aconteceu. Como resultados, verificou-se que a JR foi implementada através de um Núcleo que é ligado à justiça, tem equipe capacitada, e, para as escolas, os alunos respondem melhor a alguém externo à instituição. Verificou-se ainda que os alunos que participaram não se envolveram em novos conflitos e as escolas mudaram a visão sobre como resolvê-los, entretanto, como a JR vinculou-se às ações do Núcleo, aconteceu de forma pontual e as escolas não se implicaram para que se tornar-se uma prática cotidiana. Conclui-se que a JR pode ser uma possibilidade para resolver conflitos e violências escolares, entretanto, pressupõe disposição de todos para que se dissemine pela instituição e propicie mudanças efetivas.

Palavras-chave: justiça restaurativa nas escolas, violência nas escolas, relação justiça e escola.
\end{abstract}

\begin{abstract}
Violence in schools is a reality worldwide and involves various forms and actors. In this direction, the Restorative Justice (RJ) in schools aims to achieve understanding among stakeholders to participate in its resoluteness. In Brazil, some experiences presuppose the instrumentalization of school actors. Thus, it is aimed to analyze the possibilities and limitations of restorative practices in a city in northeastern Brazil. Therefore, 12 semi-structured interviews were conducted with representatives of the schools where the practices served. As
\end{abstract}

\footnotetext{
${ }^{1}$ Mestre em Psicologia pelo programa de Pós-Graduação em Psicologia da Universidade Federal do Rio Grande do Norte (UFRN). Psicóloga no Centro-dia de referência para pessoa com deficiência em Natal/RN. Membro da Comissão de Educação do Conselho Regional de Psicologia - CRP/17. E-mail: arthemisnuamma7@gmail.com.

${ }^{2}$ Professora do Departamento de Psicologia da Universidade Federal do Rio Grande do Norte e Coordenadora do Observatório da População Infantojuvenil em Contextos de Violência (OBIJUV). E-mail: ilanapaiva@hotmail.com.

${ }^{3}$ Professora adjunta do curso de Psicologia da Universidade Federal do Rio Grande do Norte (UFRN), lotada na Faculdade de Ciências da Saúde do Trairi. Possui graduação (2004), mestrado (2006), doutorado (2014) e estágio pós-doutoral (2015-2017) pela UFRN. E-mail: analudmila@gmail.com.
} 
outcomes, the RJ was implanted by a Center of a justice that have qualified team and, for schools, the students respond better to someone outside the institution. It was also found that the students who participated were not involved in new conflicts and schools have changed their vision on how to solve them, however, as the RJ linked to the actions of the Center, it was poorly spread and schools did not involve so it could become a routine practice. It is concluded that $R J$ may be a possibility to resolve conflicts and violence in schools, however, presupposes disposal of all so that it can be spread by the institution and triggers effective changes.

Keywords: restorative justice in schools, violence in schools, justice and school relationship.

\section{Introdução}

É comum ouvir em noticiários televisivos, jornais, rádio, e mais atualmente na internet, questões relacionadas à violência nas escolas. São práticas que vêm sendo relatadas em escolas de todo o mundo e tem despertado o interesse em uma linha de investigação, notadamente na última década do século XX, que incialmente se denominou Segurança nas Escolas e hoje em dia é mais conhecida por Violência nas Escolas (ASSIS; MARRIEL, 2010).

O que esses casos mais divulgados parecem ter de semelhante? Muito provavelmente o fato de, essencialmente, os alunos serem os principais algozes dessas ações. Mas, será que a violência ocorre e é perpetrada pelos estudantes? Como a escola pode se implicar nisso? E qual a responsabilidade da sociedade?

Ristum (2010) aponta que a expressão da violência escolar se dá sob várias modalidades: violência entre alunos, entre alunos e professores, da escola e do professor contra o aluno, entre os professores, do sistema de ensino contra a escola e o professor, dos funcionários contra os alunos, do aluno contra o patrimônio da escola, entre outras. Dessa forma, no ambiente escolar as situações de conflitos são protagonizadas por diversos atores.

Assim, é importante considerar que a escola está inserida na sociedade e constitui-se como um microcosmo diante do seu contexto mais amplo. No que concerne à violência, especificamente, aqui é vista como um fenômeno complexo, uma vez que envolve diversas dimensões da experiência humana; multideterminada porque para sua compreensão se necessita considerar aspectos históricos, sociais, econômicos, cul- 
turais, psicossociais, etc.; e, é um fenômeno multifacetado - não é apenas o crime, por exemplo -, uma vez que se manifesta de diversas formas, seja na relação entre os homens, com o mundo e consigo mesmo (TRASSI; MALVASI, 2010). Portanto, precisa ser analisada em sua raiz e profundidade.

Faz-se necessária fazer uma breve diferenciação e relação entre conflito e violência. Os conflitos, de uma maneira geral, fazem parte da experiência humana e se apresentam na sociedade na medida em que surgem quando existe diversidade, percepções distintas, bem como interesses e objetivos diversos entre as pessoas. Assim, quando essas formas e percepções diferentes se chocam, ocorre o conflito que pode se dar na família, escola ou comunidade (representando em nível micro); dentro do bairro, cidade ou região (nível meso); e, entre países (nível macro). Os conflitos não são necessariamente violentos e nem negativos, podendo inclusive ser possibilidade de crescimento quando permite que seja trabalhado eficientemente (TERRE DES HOMMES LAUSANNE NO BRASIL, 2013). Assim, são elementos estruturais dos relacionamentos e sua perspectiva construtiva presume que seja trabalhado para que possa ser transformado e supere a situação conflituosa. Ao contrário, quando o conflito é negado, pode gerar violência porque representa negar a diferença, a possibilidade do contrário, ou seja, quando não há mediação dos conflitos ou quando estes são resolvidos de forma inadequada, pode ocorrer a violência (SECRETARIA DA EDUCAÇÃO, 2009).

Na esfera escolar, as diversas formas de expressão da violência geram, portanto, uma sensação de insegurança que se dissemina: no caso dos professores, que muitas vezes não estão preparados para enfrentar esta realidade, assim como dos pais que temem as ameaças e entendem o fenômeno como uma questão de controle dos filhos, e, dos alunos que se amedrontam com as diversas situações de conflito e violência e, muitas vezes, abandonam as escolas. Todo esse conjunto de problemáticas acaba levando a um esvaziamento em algumas escolas públicas que, em geral, parecem estar sendo abandonadas tanto pelos alunos quanto pelos funcionários, dado o avanço da violência física - e emocional, inclusive (LAWRENZ; RAVA, 2012).

Outro ponto importante é que por ser um local no qual crianças, adolescentes e jovens passam a maior parte de seu tempo, as constantes transformações na sociedade 
exigem das escolas e, do sistema educativo como um todo, novas estratégias para lidar com aspectos das dimensões em que crianças e adolescentes possam se inserir, privilegiando, assim, a perspectiva de exercício de cidadania e, por consequência, garantia de direitos de todos (POLETTO; POLETTO, 2013).

Dessa forma, é interessante refletir, desenvolver e avaliar estratégias para repensar o conflito e a violência escolar, bem como, criar mecanismos para sua prevenção, levando em consideração as possibilidades a serem desenvolvidas e os seus limites, tendo em mente que a violência é mais complexa do que podem alcançar ações pontuais.

Nessa direção, um método alternativo de resolução de conflitos tem ingressado no contexto escolar, a Justiça Restaurativa (JR), que tem mostrado resultados considerados satisfatórios nas mais variadas esferas em que se insere, tanto nas questões que envolvem o conflito criminal de menor potencial ofensivo (Juizados Especiais Criminais), quanto nos casos de conflito juvenil (atos infracionais) e nos conflitos escolares e comunitários (ORSINI; LARA, 2012). Assim, em várias partes do mundo, e, especificamente sobre a realidade brasileira, existem experiências de Justiça Restaurativa nos mais variados contextos: educacional, comunitário, nas medidas socioeducativas, nos crimes de menor potencial ofensivo, etc., levando a entender que se propaga um movimento de proliferação das formas alternativas e não violentas de resolver os conflitos, bem como, a busca para se repensar o sistema de justiça atual.

A origem das ideias sobre a Justiça Restaurativa tem aproximadamente 40 anos, a partir da década de 1970 quando os primeiros registros foram verificados nos Estados Unidos através de mediação entre vítima e ofensor. Esse movimento se dá como resposta à ineficiência do modelo processual e penal que ainda perdura, e, em muitos casos, em vez de efetivamente contribuir para diminuir os conflitos sociais, aumenta e aprofunda as questões (AGUIAR, 2009).

Essa delimitação temporal diz respeito ao campo moderno da JR, mas o movimento restaurativo tem origens mais antigas, tanto quanto a história da humanidade, nas palavras de Zehr (2012), nas tradições culturais e religiosas das tribos de nativos da América do Norte e Nova Zelândia. De acordo com Nunes (2011) esses povos resolvem 
seus conflitos interpessoais fazendo reuniões com amplo debate em que participam a vítima e o agressor buscando a restauração da relação, além disso, familiares, amigos, líderes comunitários e religiosos também podem participar e contribuir.

Entretanto, é somente nos anos 1990 que a JR e seus programas se destacam internacionalmente, e, se disseminam para países como: Austrália, Canadá, Estados Unidos, África do Sul, Argentina, Colômbia, dentre outros. Em 1990, ainda, foi publicada a Changing lenses: a new focus for crime and justice (Trocando as lentes: um novo foco sobre crime e justiça) de Howard Zehr, que é considerada obra fundamental e uma marco para afirmação da Justiça Restaurativa, enquanto novo modelo de justiça, revolucionando ao colocar as necessidades da vítima como ponto inicial do processo. Ao mesmo tempo, o modelo de Justiça Penal Retributiva começou a ser questionado pela doutrina especializada (ORSINI; LARA, 2012).

Resumindo, a Justiça Restaurativa é fruto de uma conjuntura complexa. Em seu início estava associada ao movimento de descriminalização, dando passagem a diversas experiências-piloto no sistema penal a partir de metade dos anos 1970 (fase experimental), sendo algumas experiências institucionalizadas nos anos 1980 (fase de institucionalização) pela adoção de medidas legislativas específicas, e, a partir dos anos 1990 passa por uma fase de expansão e se insere em todas as etapas do processo penal (JACCOUND, 2005). A conjuntura de disseminação dessa forma de se fazer justiça influenciou o Conselho Econômico e Social da Organização das Nações Unidas (ONU) a requisitar, através da Resolução 1.999/26, de 28 de julho de 1999, à Comissão de Prevenção do Crime e de Justiça Criminal que considerasse a adoção da medição e Justiça Restaurativa pelas Nações Unidas.

Como consequência desse movimento de expansão mundial, a Justiça Restaurativa chega ao Brasil principalmente a partir da observação e estudo do direito comparado. No entanto, os modelos aplicados no país não são exatamente iguais aos estrangeiros, especialmente, porque precisa de mudanças legislativas para que possam ser positivados no direito brasileiro. Além disso, a Justiça Restaurativa precisa se adequar à realidade onde se insere (PINHO, 2009).

Assim, no final de 2004 e início de 2005, o projeto "Promovendo Práticas Res- 
taurativas no Sistema de Justiça" foi desenvolvido pela Secretaria de Reforma do Judiciário, do Ministério da Justiça, com o apoio do Programa das Nações Unidas para o Desenvolvimento (PNUD), e inicia ações mais representativas da Justiça Restaurativa no Brasil através da implantação de três projetos-piloto, nas seguintes localidades: Porto Alegre/RS, implantado na execução de medidas socioeducativas, na 3 ${ }^{\text {a }}$ Vara da Infância e Juventude; no Distrito Federal no Juizado Especial Criminal do Núcleo Bandeirante; e em São Caetano do Sul/SP, nas escolas por meio de câmaras ou círculos restaurativos, de modo a reduzir o número de conflitos encaminhados ao judiciário. Nesse sentido, através desse projeto do Ministério da Justiça foram implementados "núcleos" de Justiça Restaurativa em vários estados brasileiros, em parceira com associações ligadas à justiça por meio de promotores, juízes entre outros. A partir disso, em 2005, a Justiça Restaurativa começa a fazer parte da realidade brasileira como se pode observar (MAIOCHI; MAIOCHI, 2015).

Cabe destacar que a Justiça Restaurativa não tem o objetivo de substituir o Sistema de Justiça Tradicional, mas opera lado a lado, como um complemento ou alternativa, cujo foco é a reparação dos danos às pessoas e a comunidade, ao invés de punir os infratores.

A Justiça Tradicional/Retributiva entende o crime como uma violação ao Estado, por isso mesmo, detém para si a responsabilidade e a execução do processo penal, de modo que uma pena seja aplicada ao crime cometido pelo infrator. Nesse processo, o conflito não é resolvido entre quem é parte disso (vítima e ofensor), não havendo responsabilização efetiva, e, tampouco os interesses são considerados.

A Justiça Restaurativa, por sua vez, representa uma alternativa ou, no mínimo, uma forma diferenciada do modelo tradicional. A JR tem seu foco na vítima baseando-se numa relação com a comunidade, sob uma perspectiva sistêmica (outros microssistemas direta ou indiretamente se envolvem para a resolução do conflito). Através de uma metodologia que pretende alcançar o entendimento entre ofensor e vítima (superando a situação de conflito e evitando ações violentas), de modo que eles participem ativa e diretamente da resolutividade do conflito. O ofensor tem oportunidade de se desculpar, sensibilizando-se e responsabilizando-se pelo dano causado. Já a vítima e a comuni- 
dade também participam, falando e ouvindo, de modo que se envolvem no processo de responsabilização. Por fim, um plano de ação é construído em conjunto, de modo que não somente danos materiais e emocionais do grupo sejam restituídos, mas suprindo necessidades conforme suas próprias definições (BECKER; BRISOLA, 2011). A ideia, então, é pensar no futuro e na restauração dos relacionamentos, ao invés de concentrarse no passado e na culpa (LAWRENZ; RAVA, 2012).

A Justiça Restaurativa, assim, se estrutura a partir de alguns pilares, os quais sejam: necessidades, papéis e obrigações, ou dito de outra maneira, os danos geram necessidades que para serem satisfeitas cada um deve assumir o seu papel e obrigações para que a restauração aconteça. A Justiça Restaurativa tem, primeiramente, o foco no dano cometido e nas necessidades que surgem a partir desse dano (ZEHR, 2012).

A Justiça Restaurativa além de se alicerçar em princípios também se baseia em valores. A associação desses elementos permite compreender e dar o tom da Justiça Restaurativa, de modo que a aplicação dos princípios presume a existência dos valores. Assim como nos princípios, a existência de valores possibilita que os programas e projetos que se intitulem de Justiça Restaurativa possam de fato ser construídos dentro dos preceitos da abordagem, aconteçam e resultem em decisões de fato restaurativas.Assim, um conjunto de teóricos consideram, pelo menos, oito valores fundamentais na Justiça Restaurativa, os quais seriam: participação, respeito, honestidade, humildade, interconexão, responsabilidade, empoderamento e esperança.

Ao trabalhar com uma busca de responsabilização participativa e coletiva, baseadas em processos dialógicos e inclusivos, a Justiça Restaurativa acaba tendo a escola como seu campo de incidência por excelência. Acredita-se que, na medida em que a JR lida com os conflitos por meio do diálogo, cumpre a função pedagógica que é da Educação (PENIDO, 2009).

Vista como uma possibilidade para lidar, então, com os conflitos escolares, a Justiça Restaurativa tem sido utilizada em diversos projetos e programas no Brasil, como por exemplo: o "Justiça e Educação: parceria para a cidadania” na cidade de São Paulo (especificamente em Heliópolis) (PENIDO, 2009); "Projeto Justiça, Educação, Comunidade: parcerias para a cidadania", no município de São Caetano do Sul-SP (BECKER; 
BRISOLA, 2011); e o Projeto Justiça para o Século 21, em Porto Alegre (LAWRENZ; RAVA, 2012), dentre tantos outros que se disseminam em direção a uma sociedade mais restaurativa, apesar dos ataques e ameaças ao sistema democrático de direitos.

O que esses programas têm em comum é o fato de, além de acontecerem no âmbito escolar, presumem uma atuação que dissemine a prática no contexto como um todo e até na comunidade, através da formação de professores, alunos ou outros membros da escola como facilitadores de processos restaurativos. Assim sendo, a ação deixa de ser meramente focada em dado conflito, para se expandir pelo ambiente escolar através da instrumentalização dos sujeitos do próprio contexto de execução. Nesse sentido, essa perspectiva desjudicializa os conflitos, dando autonomia para as escolas resolverem suas questões.

Nesses casos, a Justiça Restaurativa inserida no campo educativo pressupõe disposição dos órgãos judiciário e educacional para a resolução de conflitos, inserindo-os em contextos mais amplos, ou seja, não somente o indivíduo ou a família, mas também a comunidade (BECKER; BRISOLA, 2011). Isso não significa que a inserção dessas práticas restaurativas no contexto escolar somente possa se dar através da parceria justiça e educação, embora seja a forma como mais tem acontecido. Por isso mesmo, alguns autores fazem uma pequena diferenciação entre Justiça Restaurativa e Práticas Restaurativas, que apesar de se basearem nos mesmos princípios, o primeiro é entendido quando há a parceria com o Judiciário, e, em sentido oposto, as Práticas Restaurativas poderiam ser vistas em sentido mais amplo e em qualquer contexto de atuação.

Tendo em vista esse cenário de conhecimento e expansão da JR em âmbitos variados e locais distintos, na cidade de Natal, Rio Grande do Norte (RN), foicriado um Núcleo, ligado à justiça do estado, que se inseriunas escolas einiciousuas atividades em 2012 com o objetivo de implantar, através de equipe multidisciplinar (com profissionais da psicologia, serviço social e direito), métodos restaurativos de resolução de conflitos nas escolas municipais, especialmente, além de desenvolver estratégias preventivas para as situações de indisciplina e de conflitos no contexto escolar.

O Núcleo atuou em diversas escolas e desenvolveu duas principais atividades, os encontros restaurativos e a ambiência restaurativa. Os encontros restaurativos são 
momentos em que os conflitos e violências são trabalhados buscando-se compreender as causas, consequências e necessidades que surgem. Já a ambiência restaurativa nas escolas são ações que visam o fomento à construção de um espaço escolar, por meio de oficinas, em que se trabalhem transversalmente os valores da Justiça Restaurativa, as quais aconteceram em quatro escolas, do total de 25 instituições em que o Núcleo planejou, prioritariamente, desenvolver as ações. Cabe destacar que o Núcleo atuou de forma contínua de 2012 até meados de 2013, quando por questões de ordem maior teve que interromper as atividades, que foram retomadas em 2015. Assim sendo, a pesquisa ser refere a esse primeiro ano de implantação e atuação

A partir disso, esse artigo apresenta um recorte dos resultados da nossa pesquisa de mestrado que buscou investigarquais foram as possiblidades e os limites da Justiça Restaurativa nas escolas públicas na cidade de Natal/RN.Oestudo se justifica em funçãodos conflitos e violências que se fazem realidade presente em muitas escolas. Portanto, pensar formas alternativas para lidar com a violência nesse contexto torna-se essencial, bem como, refletir sobre o fato de Justiça Restaurativa apresentar-se como avanço, mas também, se debruçar sobre os limites dessas práticas, em funçãodas especificidades de cada localidade em quepossa ser implementada.

\section{Método}

A pesquisa aconteceu em 12 escolas públicas municipais da cidade de Natal/RN no ano de 2015, as quais tiveram atuação mais contínua do Núcleocom maior intervenção de casos, dentre as quais, em quatro também aconteceu a ambiência restaurativa já mencionada na introdução.Para ter acesso as informações, realizou-se contato prévio com a equipe do Núcleo que disponibilizou os relatórios de produtividade e ações, além de consentir anuência à pesquisa. Cabe destacar também que a primeira autora foi estagiária do referido Núcleo no ano de 2013, ou seja, anteriormente à coleta de dados. Portanto, essa pesquisa pode contribuir ainda para que possam ser evidenciadas as implicações do trabalho realizado, embora nosso objetivo não seja fazer uma avaliação da implantação do Núcleo, mas como a JR se inseriu nas escolas, suas contribuições e limites. 


\subsection{Participantes, instrumentos e procedimentos de coleta}

Participaram da pesquisa 12 representantes escolares (coordenador, diretor ou vice-diretor) porque foram as pessoas nas instituições que acompanharam as intervenções de Justiça Restaurativa em suas respectivas escola, sendo 11 pessoas do sexo feminino e uma do sexo masculino. Utilizou-se um roteiro de entrevistas semiestruturadas, previamente testado, que se divide em duas partes.Na primeira,constam os dados sociodemográficos sobre as escolas e os entrevistados. Na segunda, têm-secinco questões semiestruturadas que dizem respeito a temas específicos:sobre a violência na escola; formas de resolução da violência na escola; a ação do Núcleo nas escolas;as possibilidades e limites da Justiça Restaurativa nas escolas; e, estratégias preventivas para a violência nas escolas.

A coleta de dados aconteceu nas próprias escolas, sendo realizado contato telefônico prévio com os participantes que foram convidados para serem entrevistados. Os sujeitos foram escolhidos observando quais atuaram no acompanhamento do Núcleo nas escolase,para tanto, utilizou-se os contatos de coordenadores e gestores (diretores e vice) que foram as figuras de referência do Núcleo nas instituições. Todas as entrevistas foram gravadas em equipamento de áudio para garantir a fidedignidade das falas que foram transcritas

\subsection{Procedimentos de Análise de Dados}

No que concerne aosprocedimentos de análise, os dados foram categorizados após a leitura exaustiva do material coletado.Para auxiliar essaorganização e elaboração decategorias, utilizou-se o software Qualitative Data Analysis (QDA) Miner para análise de dados qualitativos e métodos mistos que foi desenvolvido pela Provalis Research. $O$ QDA MINERpossibilita que os pesquisadores insiram dados (textos e/ou imagens), para que possam gerenciá-los através da criação de códigos e categorias que ao serem selecionados e demarcados em partes dos dados já inseridos no QDA, podem ser resgatados conforme solicitação feita na aba "análise", que congrega diversos tipos.

Feita a inserção no QDA das entrevistas transcritas, o material foi lido diversas vezes para poder criar as categorias de análise. Assim, os dados resultaram em cinco categorizações que se agrupam no código "A Justiça Restaurativa nas Escolas”, as quais 
sejam:desenvolvimento da Justiça Restaurativa nas escolas; entendimentos a cerca da Justiça Restaurativa; relações entre escola e justiça; avanços da Justiça Restaurativa nas escolas; e, limites daJustiça Restaurativa nas escolas.

Após isso, essas categorias foram descritas e selecionados alguns trechos representativos de cada uma de modo que pudéssemos analisar o que a teoria sobre JR diz a respeito. Confrontando os dados da realidade com a conceitualização teórica em uma perspectiva crítica de análise.

\subsection{Procedimentos Éticos}

A pesquisa passou por apreciação de Comitê de Ética em Pesquisa sendo aprovada. Visando garantir os cuidados éticos, obteve-se a anuência da Secretaria Municipal de Educação e todos os participantes assinaramTermo de Consentimento Livre e Esclarecido (TCLE) e Termo de Autorização para Gravação de Voz. Para assegurar a confidencialidade e sigilo das informações, a identidade dos participantes foi preservada mediante a utilização de nomes fictícios. Assim, optou-se por chamá-los de participantes $A, B, C, D, E, F, G, H, I, J, K$, e $L$ nomeados de forma aleatória e as escolas foram numeradas de 1 a 12. Ainda como forma de garantir o anonimato, o nome do Núcleo e toda informação que pudesse identifica-lo foi retirada e será nomeado dessa maneira.

\section{Análise e discussão dos resultados}

Nesse tópico são discutidas as experiências que as escolas municipais de $\mathrm{Na}$ tal/RN tiveram com a Justiça Restaurativa, através das ações do Núcleo (que atividades foram desenvolvidas, como e quem participou), mas também de que maneira essa forma de resolver conflitos pode se constituir como uma prática das instituições escolares (como a compreenderam, se a utilizam no seu cotidiano, quais as possibilidades e os limites). Além disso, é importante discutir as relações entre escola e justiça. Para organizar a análise, foram construídas cinco categorias a partir da leitura dos dados constantes nas doze entrevistas semiestruturadas, as quais sejam: desenvolvimento das práticas restaurativas; entendimentos acerca da Justiça Restaurativa; relações entre escola e justiça; avanços das práticas restaurativas; e, limites das práticas restaurativas.

Cabe destacar que não é o intuito dessa pesquisa avaliar as ações do Núcleo, 
tampouco como as escolas resolvem suas situações de conflitos e violências, mas problematizar de que maneira a Justiça Restaurativa pode contribuir para resolver essas questões escolares, inclusive se pode ou não se constituir como uma prática das instituições, no sentido de adequação ao contexto escolar, se e como a abordagem restaurativa é passível de utilização nas escolas e que ajustes são necessários para sua efetiva utilização, a disposição das instituições para isso (tempo, pessoal e concepções sobre conflitos e violências) e parcerias necessárias, como a do Núcleo. Ainda salientase que apesar da JR se expandir pelo Brasil ao longo desses anos, e nos mais variados contextos, não acontece da mesma maneira em cada tempo e espaço, existem as especificidades locais que caracterizam a sua implementação em dada localidade, seja o público atendido, quem executa, etc.

Antes de discutir as categorias de análise, é importante caracterizar as escolas e os sujeitos de pesquisa. Metade das instituições se localiza em bairros considerados em vulnerabilidade social e integram a Zona Norte da cidade, considerada a mais violenta se comparada às demais regiões administrativas, que em 2014, por exemplo, teve índice absoluto de 239 casos de Crimes Violentos Intencionais Letais ${ }^{4}$ (CVLIs) (HERMES; ALVES, 2015).

A maioria das escolas possui um número elevado de alunos e, sendo assim, são diversas as demandas para lidar cotidianamente, especialmente, no quesito indisciplina, conflitos e violências. Das 12 instituições, 10 (dez) tem, aproximadamente, entre 500 e 1200 alunos. Dentro dessa faixa, seis escolas têm os Ensinos Fundamentais I (do 1ํao 5ano) e II (do 6ำ ao 9ำ ano) - apesar de que duas delas não apresentam todos os anos; duas tem o Ensino Fundamental I; e, duas tem o Ensino Fundamental II. Todas apresentam o Ensino Fundamental no período diurno, embora algumas também possuam a Educação de Jovens e Adultos (EJA) no período noturno euma tem o Programa Nacional de Inclusão de Jovens (Projovem). Por fim, completando as 12 escolas pesquisadas,

\footnotetext{
${ }^{4} \mathrm{Na}$ obra do Homicímetro ao Cvlicímetro: a plataforma multifonte e a contribuição social nas políticas públicas de segurança (2014), Ivenio Hermes e Marcos Dionísio explicitam o Crime Violento Intencional Letal (CVLI) e o diferencia do homicídio doloso, ao demonstrar que o primeiro contempla uma gama de variáveis que em conjunto podem resultar em um melhor indicador do grau de violência. Assim sendo, se utiliza de várias informações que resultam na Plataforma Multifonte, que conta com diversos atores que atuam como fontes sociais e contribuem para alimentar o banco de dados. Essa plataforma já foi utilizada em outros lugares no Brasil e desde 2013 vem sendo testada e aprimorada no Rio Grande do Norte.
} 
duas tem o número de alunos inferior à faixa predominante, sendo uma com 360 alunos e outra com 164, e, ambas possuem apenas o Ensino Fundamental I.

Diante disso, como relatado nas entrevistas, os profissionais tem que criar estratégias para prevenir situações de violência e algumas escolas dividem os níveis por turno ou ainda algumas dividem o intervalo em dois momentos, concentrando os alunos maiores em um período e os menores em outro, inclusive com relatos de melhoras nas situações conflituosas que aconteciam. Cabe ainda mencionar que algumas escolas informaram ter uma estrutura menor do que a demanda de alunos exige, bem como limitações espaciais no que se refere a lugares para lazer, como falta de quadra de esportes, o que segundo relatos dos entrevistados, poderia ser muito útil porque os alunos não precisariam disputar espaço e nem se machucar ao esbarrar, até eventualmente, uns nos outros.

No que diz respeito as 12 pessoas entrevistadas, 11 são do sexo feminino e somente uma é do sexo masculino, o que demonstra, ao menos na amostra, uma predominância de mulheres no espaço escolar, seja nas funções de gestão ou coordenação. Em relação à faixa etária dos participantes, as idades variam entre 34 e 59 anos. Sobre o cargo ocupado, metade dos entrevistados estava na gestão escolar, seja na direção (quatro pessoas) ou na vice direção (duas pessoas), os quais exigemuma jornada de 40h semanais. A outra metade ocupa o cargo de coordenação pedagógica. Dessa metade de coordenadores, apenas três pessoas tem vínculo com outra escola, e, portanto, exercem uma carga horária de $20 \mathrm{~h}$ na escola em que foi feita a coleta.

Essa questão de carga horária na instituição é interessante porque, de acordo com os relatos nas entrevistas, os profissionais trabalham com inúmeras demandas e o tempo é limitado em função do trabalho diário, assim sendo, a execução de trabalhos extras, como projetos de prevenção e resolução de conflitos e violências, inclusive a utilização da justiça restaurativa, pode ser comprometida porque demanda material humano para executar e disponibilidade de tempo livre, o que, muitas vezes, não acontece. Some-se a isso que os profissionais que trabalham em outra escola tem o tempo mais limitado não somente porque tem que trabalhar o resto do dia em outra instituição, mas também em função dos deslocamentos, o que dificulta ainda mais a execução de qualquer atividade 
extra. Nesse ponto, observa-se que três entrevistados moram no mesmo bairro da escola pesquisada; quatro em bairros próximos e na mesma região administrativa; e, os cinco que restam moram em bairros distantes do bairro em que a escola se localiza. Morar no mesmo bairro da escola é importante porque o profissional acaba entendendo um pouco do contexto dos alunos por conhecer a comunidade e minimamente saber as demandas daquela região, além de estar na mesma localidade ser uma vantagem para não perde tempo em deslocamento.

Para além dessas questões de ordem mais prática, os entrevistados relataram que gostariam de ter maior participação das famílias no ambiente escolar; relataram não ter parceiros institucionais que pudessem contribuir para resolver a demanda de conflitos e violências; algumas escolas questionam se é ou não sua função, ou da família, resolver tais situações; as diversas atividades ao longo do turno de trabalho, assim sendo, coordenadores, diretores e vices - principais atores escolares mencionados como os responsáveis para resolver tais situações -, além dos professores, sentem-se sobrecarregados, o que contribui para que o tempo dedicado às resoluções de conflitos e violências seja menor.

Por tudo isso, essa é a realidade que a Justiça Restaurativa encontrounas escolas municipais investigadas e que vai servir de base para a configuração das ações e necessidade de lidar com as especificidades para realizar um trabalho de qualidade e que traga bons resultados, possibilitando que as escolas possam ser espaços de aprendizagem seguros e com relações amistosas entre os membros da comunidade escolar.

\subsection{Desenvolvimentoda Justiça Restaurativa nas Escolas}

A categoria em questão refere-se a como o Núcleo chegou às instituições pesquisadas, as ações desenvolvidas, como foram executadas e quem participou. Ao perguntar como o Núcleo chegou às instituições,percebeu-se que houve diferenças na forma de apresentação inicial às escolas. Em algumas, foi através de ofício informativo; em outras se deu mediantevisita às escolas; ou ainda através da Promotoria de Justiça da Educação do Ministério Público, a qual o Núcleo se vincula.

Uma vez que as escolas conheciam o Núcleo, este passou a atuar sempre que solicitado e através de visitas institucionais e de captação de conflitos. Nas primeiras 
visitas, o Núcleo conversou com a direção e coordenação das escolas como uma maneira de fazer um diagnóstico institucional para saber como resolviam as questões de indisciplina e violência. Sendo assim, esses atores da comunidade escolar passaram a ser as pessoas de referência nas escolas, já que em sua maioria os conflitos eram comunicados ao Núcleo através deles. Outra ferramenta utilizada incialmente foi a análise dos livros de ocorrências.

O Núcleo desenvolveu três tipos de ações, de acordo com os entrevistados: orientações, formações e encontros restaurativos. No campo da orientação, algumas escolas relataram que, em casos específicos, não precisaram da atuação do Núcleo diretamente no conflito ou violência, mas, foram orientadas a como agir e a fazer o registropara ter estatísticas das violências nas escolas a cada ano. As formações eram chamadas pelo Núcleo de ambiência restaurativa e dizem respeito às ações que preventivamente buscam criar um ambiente saudável para que as relações aconteçam de forma positiva com a resolução pacífica dos conflitos. Os entrevistados comentaram que participaram de formações e foramrealizadas palestras nas escolas, com alunos, gestores, coordenadores, professores, funcionários, etc. Essa atividade pareceu ser menos frequente quando comparada às demais ações, entretanto, quando aconteceu foi vista de forma positiva e necessária, inclusive quando se falam dos limites da atuação.

A última atividade desenvolvida foi o chamado encontro restaurativo, que se divide em três etapas: o pré-círculo, no qual se conversa com os envolvidos individualmente e ouve-se o que cada um tem a dizer, convidando-os para participar da etapa seguinte;no círculo restaurativo a ofensa é trabalhada e conta com a participação de todos que se envolveram direta e indiretamente na situação (vítima, agressor, familiares, comunidade e facilitadores) para buscar sua resolução coletiva; e, por fim, o pós-círculo para acompanhar se o que foi decidido no círculo está sendo cumprido. Todas as escolas passaram por essas três etapas do encontro restaurativo, umas mais e outras menos.

E quem participava dos círculos restaurativos? É interessante observar que essa participação variou de escola para escola, assim como o local onde os encontros aconteciam (podendo ser nas próprias escolas ou na sede do Núcleo no Ministério Público). Em todos os casos, os envolvidos nas situações conflituosas e de violências participaram dos 
círculos restaurativos; em boa parte, os representantes escolares também participaram, mas houve casos em que isso não aconteceu; a família também participou bastante, mas da mesma forma, não foi sempre convidada a participar. Em poucos casos os professores participaram (somente repassando informações sobre os alunos ou quando eles próprios eram partes do caso), e, em nenhum círculo restaurativo representantes da comunidade participaram.

Essa provável exclusão de alguns interessados nessas situações compromete a forma como a Justiça Restaurativa tradicionalmente acontece e entende as ofensas e os crimes: como violações da pessoa e dos relacionamentos, nesse sentido, não somente o ofensor e a vítima são afetados, mas a comunidade, uma vez que tais ações rompem com o sentido de inteireza do tecido social (ZEHR, 2008). Ao mesmo tempo, deve-se problematizar que a intervenção ainda estava em fase de experimentação e convidar participantes que ainda não estivessem alinhados com os valores e princípios restaurativospoderia comprometer os resultados esperados.

Além disso, concentrar as ações na figura de representantes escolares específicos, como os coordenadores e gestores, talvez tenha contribuído para que a Justiça Restaurativa não se disseminasse pela escola. Assim, os momentos formativos também são interessantes e precisam acontecer com maior frequência para atores diversos nas escolas, mas, depende de disposição das instituições para acontecer e tempo suficiente, inclusive do Núcleo.

Cabe destacar que o Núcleo atuou, de acordo com os entrevistados, nos casos que as escolasnão conseguiam solucionar, servindo como um recurso nesses momentos difíceis. Inclusive, algumasrelataram a importância dessa parceria,já quese sentem isoladas, sem uma rede de apoio, que deveria existir, como demonstrado na fala a seguir: "[...] como eu já falei anteriormente, o que a gente pode resolver, a gentevai resolvendo, certo; então, digamos assim, o núcleo é para nós uma carta na manga, quando a gente não consegue, então a gente chama [...]"(Participante B, Escola 2).

Todos esses elementos demonstram que a JR e sua prática são adaptadas à realidade escolar, funcionando a partir do contexto em que se insere. Além do mais, varia conforme quem executa, por isso, as estratégias de aproximação, registros, local em que- 
acontece, quem deve participar, também são influenciados pelo momento e experiências dos facilitadores.

Ao se comparar a forma de atuação do Núcleo e das escolas para resolver os conflitos e violências pode-se perceber que acontecem de maneira semelhante. Em ambos os casos o diálogo é o instrumento essencial de trabalho; todos os envolvidos são ouvidos; e, são feitos os registros dos casos tanto nos procedimentos das escolas quanto do Núcleo. Nesse sentido, quando os entrevistados foram questionados sobre o que o Núcleo, então, acrescenta ou traz de diferente às ações já desenvolvidas pelas escolas, os entrevistados elencaram diversos pontos que serão explicitados adiante.

\subsection{Entendimentos acerca da Justiça Restaurativa}

Nessa categoria, discute-se o que os participantes entendem por Justiça Restaurativa ou Práticas Restaurativas. Os entrevistados demonstraram compreender o significado da Justiça Restaurativa e como acontece, entretanto, para a maioria, a sua compreensão está intimamente relacionada ao que o Núcleo fez e ao que é, portanto, limita-se ao conhecimento prático, como se observa no trecho a seguir: "a Justiça Restaurativa?Eu num sei se eu posso chamar de órgão?Eu acho que é um órgão da justiça que está aí pra ajudar, né, principalmente no meio escolar a acabar com a agressão [...]" (Participante I, Escola 9).

Sobre os entendimentos propriamente ditos, os entrevistados utilizaram o próprio termo para ajudar a explicitar suas concepções, assim, para os participantes a JR é "restaurar o humano", "restaurar as alianças", "a confiança quebrada","restaurar os elos de amizade quebrados", "restaurar a paz", "restaurar o que não tá bem”,"restaurar aquela ferida que foi criada", "restaurar o ambiente que a escola tem que ter, que é um ambiente acolhedor", "um novo olhar para a mudança", etc.

Dessa forma, as expressões utilizadas de fato consideram os objetivos da Justiça Restaurativa, ou seja, trabalhar os conflitos, crimes e violências de modo a restaurar o tecido social rompido e, para tanto, é preciso uma mudança de postura.

Nessa lógica de transformação, a forma como o conflito e sua resolução são vistos se diferencia e importa-se com a relação e não atribuição de culpa para aplicar uma 
punição. Para Aguiar (2009), a Justiça Restaurativa é entendida como uma reformulação do que se entende por justiça e busca trabalhar a compreensão sobre as situações conflituosas primando pela humanização do processo ao procurar identificar as necessidades dos envolvidos (direta e indiretamente), bem como sua responsabilização para que, de alguma forma, comprometam-se e construam uma solução. Assim, a JR se constitui como um novo paradigma para olhar a situação conflituosa e assume um caráter participativo, uma vez que as partes envolvidas atuam na construção do processo decisório em direção a uma solução transformadora.

Por tudo isso, os entrevistados compreendem o que de fato é a abordagem da Justiça Restaurativa. Por outro lado, entender a JR restrita ao Núcleo desobriga as escolas a buscarem compreender o método e usar no cotidiano. Portanto, é importante que compreendam que a JR transpõe a atuação do Núcleo e pode se inserir no cotidiano escolar, com os próprios profissionais das escolas sendo protagonistas do processo.

\subsection{Relações entre Escola e Justiça}

Essa categoria diz respeito à relação que se estabelece entre a escola e a justiça e busca compreender de que maneira esse envolvimento interfere na comunidade escolar. A base dessa categoria está na escola fazer um trabalho semelhante ao realizado pelo núcleo. Nesse sentido, quando as escolas foram questionadas sobre o que a JR acrescenta à forma como já trabalham, um dos pontos relatados foi o respaldo legal do Núcleo.

O primeiro elemento dessa relação é o Núcleo ser um órgão da justiça, que segundo um dos entrevistados tem mais autoridade do que a escola. Além disso, dá respaldo legal e legitima as ações em que as escolas se sentiam inseguras de executar. Some-se a isso que tem um peso ser justiça porque os pais e alunos veemcom mais seriedade, e, muitas vezes, é preciso um agente externo à instituição para resolver os problemas da escola, já que os alunos estão acostumados com os profissionais da instituição e pode não surtir efeito esperado, conforme relatado. Sobre essa visão positiva e de credibilidade da justiça, um dos profissionais entrevistados ainda acrescentou que sua presença na escola é uma forma de trabalhar os direitos e ser um caminho para o acesso à justiça de uma parcela da população que não tem isso no seu cotidiano. 
Ao mesmo tempo, a justiça na escola é um fator intimidador. Em várias instituições, incialmente, os pais e alunos ficaram receosos com a Justiça Restaurativa ser do âmbito jurídico. Em algumas escolas, inclusive, os gestores e coordenadores omitiram a informação que se tratava da justiça, como no exemplo: "[...] a gente não explicou isso pra ninguém, pra os pais quando eu comunicava [...] o pessoal da Justiça Restaurativa, justiça né, aí o pai já ficava meio assustado, então isso talvez intimidasse para que a coisa fluísse" (Participante L, Escola 12).Em outros casos, após a compreensão das ações e passado "o susto inicial", alunos e pais entendiam como importante.

Em função desse caráter intimidador, é importante pensar de que maneira isso pode afetar a voluntariedade para participar do encontro restaurativo. Assim, problematizar em que medida os participantes podemefetivamente escolher participar ou não, se conheciam a proposta, se sabiam com que estavam falando, etc., apresentando-se a JR como uma possibilidade e não mais uma forma de punição. Nesse quesito, uma prática de JR deve ter como um dos requisitos iniciais a concordância em participar do processo (AGUIAR, 2009), ou seja, "a participação é estritamente voluntária, e a aceitação, da alternativa restaurativa, não pode ser imposta em quaisquer situações" (PINHO, 2009, p. 248).

Um segundo elemento trazido pelos entrevistados foi o fato do Núcleo possuir equipe técnica especializada, com profissionais adequados para lidar com questões de conflitos e violências. Segundo os entrevistados, eles estariam mais instrumentalizados do que a escola para resolver tais situações, inclusive as famílias dos alunos escutam melhor os profissionais por estarem tecnicamente mais preparados.

Todos esses elementos trazidos ressaltam a visão de que a escola aceita a entrada da JR em função de àescola ser atribuída aresponsabilidadepara resolver os conflitos e violências que não se sente preparada para lidar, aà falta de tempo devido asdiversas atividades que desenvolve, por achar que não é seu papel, dentre tantos outros motivos que parecem justificar e demonstrar a necessidade da presença de alguém para se dedicar exclusivamente a essa função. Assim sendo, se a escola já realiza um trabaIho semelhante ao Núcleo, porque não poderia acrescentar o que a JR traz de novidade? Delegando uma de suas funções para alguém externo à instituição não deslegitima a au- 
tonomia escolar para resolver seus conflitos e violências? Ou seja, as suas ações não estariam sendo substituídas?

Como se pode perceber no percurso realizado até aqui, existe uma lógica que atravessa todas as categorias, o fato das escolas, em certo sentido, necessitarem se desresponsabilizar por essa função de mediadoras de conflitos no seu interior. Então, alguém vir até a escola, resolver os problemas, ter respaldo legal, não utilizar uma postura punitiva, não interferir nas atividades diárias, manter diálogo com as famílias, inclusive através de visitas domiciliares, preenche lacunas que as instituições ainda não tem condições de fazer. Além do mais, é cômodo para as instituições. Apesar disso, todos os entrevistados ao serem questionados não acham que a autonomia da escola seja comprometida com alguém de fora das instituições vir resolver situações de sua competência, ao contrário, enxergam como parceiros e um apoio que não encontram em nenhuma outra instituição pública. Portanto, não encaram como uma substituição do papel da escola, porque não perdem a autonomia já que, segundo eles, participam dos processos acompanhando e se informando a cada nova medida, uma vezque o Núcleotem diálogo constante com a escola.

Apesar de todos esses elementos fazerem sentido dentro da dinâmica escolar, somados ao fato da prática da JR ser atrelada ao Núcleo,eles também distanciam as escolasda função de executoras dessas novas ações. Portanto, a JR precisaria ser efetivamente realizada pelos diversos atores da comunidade escolar, e assim, poder se disseminar por toda a instituição com a participação coletiva. Porque do contrário, quando a escola delega sua responsabilidade em intervir nas situações que the cabem, dentro do seu próprio espaço, associada à falta de apoio de órgãos como o Conselho Tutelar, que deveria dar respaldo, e a falta de estratégias preventivas educativas para enfrentar as situações de violências no seu interior, podem causar a judicialização das relações escolares (AGUINSKY; AVILA; PACHECO, 2014).

Assim, mesmo que o Núcleo tenha um papel importante na desjudicialização dos conflitos e violências escolares, porque é seu escopo atuar de forma preventiva e evitar agravamentos de qualquer natureza, atuando inclusive dentro da escola, tem-se que ter cuidado ainda com o papel que ajustiça representa na sociedade, e, portanto, é preciso 
desmitificar a visão da justiça apenas em seu caráter repressivo e disciplinador.

\subsection{Avanços da Justiça Restaurativa nas Escolas}

Nessa categoria, discute-se o que efetivamente as práticas trouxeram de avanços para a resolução de conflitos e violências nas escolas. No tópico anterior, percebe-se que a relação das escolas com a Justiça Restaurativa se deu influenciada pela ação do Núcleo, portanto, alguns dos benefícios trazidos pela ação prática se vinculam diretamente ao trabalho realizado pelo Núcleo.

Apesar disso, buscando transpor a simples atuação de um órgão externo no interior da escola e superando a visão de avaliação das ações, dois elementos importantes se colocam como avanços das práticas restaurativas propriamente ditas, ou seja, a despeito da relação justiça e escola, a abordagem restaurativa trouxe alguns benefícios que foram incluídos no trato dessas questões, quais sejam: inibição de novos conflitos entre os alunos que participaram dos círculos restaurativos, e, a JR redimensionou a forma como as escolas lidam com os conflitos e violências.

Sobre o primeiro ponto, todos os entrevistados relataram que os alunos que participaram das intervenções do Núcleo não voltaram a cometer atos de violência e nem se envolver em conflitos, especialmente, entre as partes da situação que foi trabalhada com a Justiça Restaurativa. Apesar disso, a Justiça Restaurativa não tem por objetivo principal reduzir a reincidência de novos casos, mas acaba sendo um subproduto dos procedimentos restaurativos (ZEHR, 2012).Ou seja, na JR o que importa é trabalhar o conflito na sua base, entendendo as causas, consequências e necessidades, buscando a verdadeira responsabilização do ofensor e isso pode produzir efeitos positivos e educativos aos envolvidos, como contribuir para que não se envolvam em novos casos.

O segundo ponto levantado como um avanço é a JR se configurar como uma possibilidade nova para a resolução dos conflitos e violências, que além de trazer resultados positivos (como diminuir a reincidência) contribui preventivamente ao se tornar a base para as relações escolares, como no caso dos entrevistados que a utilizam no seu dia a dia, tendo uma postura restaurativa nas relações e atividades, ou ainda, ao mudar a perspectiva de visualização das ações quando do acontecimento dos conflitos, procurando trabalhar os casos em vez de se utilizar de medidas punitivas: "[...] como eu disse 
a você, o meu comentário anterior já foi uma visão a partir da reflexão do Núcleo né. É... expulsar um aluno, transferir um aluno, dar uma suspenção; isso resolve o conflito? Não, não resolve" (Participante $\mathrm{B}$, Escola 2).

Isso se amplia nas escolas que já buscavam uma postura mais compreensiva no trato dos conflitos e violências, entretanto, a abordagem restaurativa possibilitou problematizar as medidas empregadas e recorrer ao diálogo verdadeiro, se colocando no lugar do outro e buscando compreender as intenções subjacentes aos conflitos para também chegar a uma solução, evitando simplesmente fazer com que os alunos se desculpem sem entender de fato como tudo aconteceu. O trecho adiante dá essa dimensão ampliada do trabalho que passa a ser executado, mesmo depois que o Núcleo parou de atuar:"[...] o núcleo sai e agente tem que dar continuidade, então, as situações elas continuaram e a gente continuou agindo dessa forma. Eu aprendi essa coisa de ouvir o outro, botar um pra falar, botar outro, se colocar no lugar"(Participante F, Escola 6).

Por tudo isso, a JR se constitui como uma importante ferramenta para lidar com conflitos e violências, especialmente no âmbito escolar em que alunos estão em processo formativo não somente dos conteúdos acadêmicos, mas é um espaço de construção de valores e da própria identidade. Sendo assim, a inserção das práticas restaurativas nas escolas deve se disseminar por todo o ambiente para que as relações se desenvolvam de maneira positiva, já que possibilitam mudanças na interação entre as pessoas (NUNES, 2011) e também se evite que os conflitos que acontecem na escola sejam judicializados, criminalizando os atos praticados, que, em muitos casos, com orientação e trabalhando o conflito podem ser solucionados.

\subsection{Limites da Justiça Restaurativa nas Escolas}

Nessa categoria analisou-se até onde a Justiça Restaurativa pode chegar e o que precisaria melhorar. Nesse ponto, foi considerado o que foi feito pelo Núcleo porque foi o executor da prática e porque as escolas falaram a respeito da sua atuação.Além disso, sobre a abordagem restaurativa em si não houve críticas no sentido de limites ou necessidade de melhorias.

De acordo com os entrevistados, foram elencados elementos para o Núcleo meIhorar: a)a extensão das ações para além dos alunos, portanto, que a JR se dissemi- 
nasse por toda a escola e na comunidade, integrando os diversos atores; b) acontecer com mais frequência; c) a paralisação das atividades do Núcleo foi vista como uma perda ecompromete a credibilidade das ações; e, por fim, d) as ações do Núcleo e da escola que esbarram na realidade fora da instituição, e embora o conflito se resolva, os alunos vivem diversas violações nos seus cotidianos extramuros escolares.

Sobre a disseminação, relataram que é importante que o Núcleo atue de modo que mais atores possam contribuir, promovendo ações que integrem a instituição, alunos e família como rodas de conversa, palestras, assessoramentos mais frequentemente, incluindo fazer um calendário para estar nas instituições, ou seja, as escolas tambémsentem necessidade de intervenções no âmbito formativo, para não se caracterizar como uma ação pontual. Sobre a necessidade de expansão para toda a escola:"[...] a própria ideia de Justiça Restaurativa deveria estar presente dentro das salas de aula, e do próprio professor, que muitas vezes não estaria trazendo esses problemas pequenos pra gente. Estaria resolvendo dentro de uma conciliação interna dentro da sua esfera" (Participante $\mathrm{H}$, Escola 8). Acrescenta-se ainda que talvez pela não disseminação suficiente na escola, muitas pessoas nem saibam que aconteceu nas instituições. Além de que, pouco foi comentado também sobre o retorno das práticas por parte de alunos que participaram, professores (quando estiveram presentes) e pais.

Como se falou, as escolas responsabilizaram o Núcleo pela disseminação ou não da JR, mas, em que medida elas tem se disponibilizado para essa ampliação da Justiça Restaurativa? Além disso, a equipe de profissionais Núcleo é pequena para a quantidade de escolas públicas (municipais e estaduais) e particulares, ou seja, impossível fazer um trabalho diário em todas as instituições. Diante dessa realidade, e da situação das escolas com diversas atividades, qual seria sua contribuição efetiva para disseminar a JR no seu interior? O primeiro passo é a disponibilidade. Não é simplesmente "quero que a escola tenha Justiça Restaurativa" e esperar pela atuação do Núcleo que deve servir como um apoio para a resolução dos conflitos, orientar e estimular a adoção das práticas pelas escolas.

De acordo com Nunes (2011) "é compreensível que os organizadores da escola tenham dificuldades para construir as condições necessárias aos funcionamentos de 
reuniões restaurativas (espaço, horários, facilitadores, murais...), pois tudo dependerá da adoção de uma nova filosofia" (p. 48). Uma solução apresentada pelo autor, é que todos da comunidade escolar possam compreender a ineficácia da proposta punitiva e visualizem a prática restaurativa como um caminho para a convivência democrática.

Obviamente que cada escola tem suas especificidades, se insere em contextos comunitários distintos, e necessitam de adaptações. Mas para que novos modelos possam ser testados, é preciso não somente a abertura para o novo, mas que a ação aconteça conjuntamente, com a participação de todos os envolvidos e que hajadisposição. Sendo assim, o limite da abordagem consiste na sua aceitação inicial, e por ser um projeto arrojado demanda tempo e disposição. Caso não haja, as ações somente continuarão acontecendo em nível pontual.

O último elemento trazido pelos entrevistados é o limite que a escola também enfrenta ao lidar com o que extrapola os muros escolares. É feito um trabalho com os alunos na escola, mas a realidade com que convivem tem um grande peso e o trabalho pode ser desfeito. Portanto, reforça ainda mais a necessidade da escola trazer a comunidade e a família para contribuir com a instituição. Portanto, precisa que também se movimente e não responsabilize quem quer que seja. As escolas já fizeram esse diagnóstico? Então agora podem pensar estratégias de aproximação, mesmo que considerem as limitações de tempo e pessoas para executar.

Isso se deve ao fato de a escola não estar isolada na sociedade, ao contrário, se constitui como um microcosmo que inclusive pode cumprir a função de reproduzir a ideologia da sociedade capitalista através da manutenção das desigualdades sociais.

De acordo com Souza, Poletto e Koller (2013) a violência crescente na sociedade, seja onde ela aconteça, está relacionada às desigualdades sociais e violação dos direitos dos cidadãos. Sobre as violações, especialmente dos direitos das crianças e adolescentes, estas ainda acontecem a despeito das inúmeras mobilizações em âmbito nacional e internacional. Com isso, concorda-se com Sampaio e Almeida (2008) que apontam que "a predominância de uma classe sobre as demais, se funda também no quadro das práticas sociais, pois as relações sociais capitalistas alicerçam a dominação econômica, cultural, ideológica e política" (p. 361). 
A violência, pois, precisa ser entendida em sua totalidade, como um fenômeno material que compõe as relações sociais de produção e reprodução na sociedade capitalista, especificamente, no contexto brasileiro.Para Asbahr e Sanches (2013) é essencial entender a sociedade capitalista porque aí será possível compreender o contexto em que a escola se insere, "embora a escola pública não seja uma unidade de produção capitalista e não esteja subordinada ao controle direto do capital, está submetida a ele de forma política e ideológica" (p.40).

Por tanto, a Justiça Restaurativa se limita quando suas formas de resolver os conflitos não vai acabar com a violência em sua raiz, embora se constitua como um importante elemento para repensar as relações sociais e de forma pontual em cada caso em que a utilize possa trazer benefícios para restaurar as relações, considerar as necessidades e coletivamente buscar a responsabilização pelos atos cometidos.

\section{Conclusão}

É essencial pensar, a despeito da visão da escola como lugar da violência, que a educação é uma importante estratégia para enfrentá-la. Assim sendo, é preciso refletir, desenvolver e avaliar estratégias para repensar o conflito e a violência escolar, bem como, criar mecanismos para sua prevenção, levando em consideração as possibilidades a serem desenvolvidas e os seus limites, dado que a violência é muito complexa para ter sua extinção através de ações pontuais.

Por tudo isso e levando em consideração que as escolas necessitam de profissionais qualificados e tem que lidar com diversas demandas diárias, comprometendo não somente os espaços para trabalhar conflitos e violências já deflagrados, mas também estratégias preventivas mais eficazes,é preciso ter disponibilidade e disposição para fazer diferente, para que de fato a realidade escolar se modifique para criar um ambiente seguro e pautado pelo respeito ao outro.

Nesse sentido, a Justiça Restaurativa se mostrou como uma estratégia interessante ao contribuir para a não reincidência de casos, ao mesmo tempo em que permitiu uma modificação na forma de enxergar os conflitos e violências, procurando trabalhar na sua base e evitar o agravamento e judicialização das ofensas, no sentido de as ocorrên- 
cias seguirem os trâmites jurídicos tradicionais. Portanto, compreende-se que o processo de implantação da Justiça Restaurativa nessas escolas municipais foi o primeiro passo para que a cultura restaurativa possa se inserir efetivamente no cotidiano escolar. Ainda mais porque a especificidade dessa experiência em relação às demais no Brasil é o fato das atividades de ambiência restaurativa aconteceram de forma pontual ou por pouco tempo. Ou seja, as ações formativas aconteceram eventualmente e não se constituíram efetivamente como espaço para instrumentalizar os atores escolares.

Além disso, é preciso que as escolas se organizem e se disponham a implementar a JR e dar continuidade, sendo autônomas e protagonistas das suas ações. Porque do contrário, tudo que puder ser experimentado na comunidade escolar não terá êxito porque depende do comprometimento, pessoas disponíveis e treinadas para por em prática a Justiça Restaurativa nas escolas.

Cabe destacar, por fim, que para além dos limites de execução nas instituições escolares, a Justiça Restaurativa enquanto método executado pelos órgãos de justiça ou em sua parceria podem, mesmo que não intencionalmente, carregar o "peso"da justiça e talvez promover uma nova forma de judicialização, já que a justiça se faz necessária. Ao mesmo tempo, as escolas podem se desresponsabilizar, uma vez que em função das diversas demandas cotidianas e com a possibilidade de a resolução seguir a partir de agentes especializados podem não se implicar nessas questões que também fazem parte do processo educativo e formação integral dos sujeitos. Portanto, é interessante o uso da JR, mas talvez seja mais apropriado considerá-la enquanto uma prática restaurativa que pode, então, ser executada por qualquer pessoa, que previamente se habilite e aplique os princípios e valores restaurativos no trato dos conflitos e violências no cotidiano escolar, comunitário, familiar, etc.

\section{Referências}

AGUIAR, C. Z. B. Mediação e Justiça Restaurativa: a humanização do Sistema Processual como forma de realização dos princípios constitucionais. São Paulo: QuartierLatin, 2009.

AGUINSKY, B. G.; AVILA, L. F.; PACHECO, C. L.Violências nas escolas que se judicializam: desafios para as Políticas públicas. In XI Seminário internacional de demandas Sociais e políticas públicas na sociedade contemporâ- 
nea e VII Mostra de trabalhos jurídicos e científicos, 2014. Disponível em : $<$ http://online.unisc.br/acadnet/anais/index.php/sidspp/article/view/11755/1545>.Acesso em: 28 abril. 2015.

ASBAHR, F. S. F.; SANCHES, Y. C. S. Transformação social: uma possibilidade da educação escolar? In:Paro,V. H. (Org.), A teoria do valor em Marx e a educação. São Paulo: Cortez, 2013.

ASSIS, S. G.; MARRIEL, N. S. M. Reflexões sobre violência e suas manifestações na escola. In S. G. Assis, P. Constantino,\& J. Q. Avanci (Orgs.), Impactos da violência na escola: um diálogo com professores. Rio de Janeiro: Ministério da Educação/FIOCRUZ, 2010. p. 41-63.

BECKER, V. A. P.; BRISOLA, E. M. A. Contexto Educacional: uma experiência em Justiça Restaurativa. Revista Ciências Humanas, 4(1), 137-148, 2011. Disponível em:<http://www.rchunitau.com.br/revista/index.php/rch/article/view/10>. Acesso em: 21 janeiro. 2014.

HERMES, I.; ALVES, C. Bellum Omnia Omnes: Natal a princesa da guerra. In I. Hermes (Org.), Metadados 2014: anuário sobre a violência no Rio Grande do Norte Natal: Ed. dos Autores, 2015. p. 69-78.

JACCOUND, M. Princípios, tendências e procedimentos que cercam a Justiça Restaurativa. In C. R. Slakmon, R. De Vitro,\& R. Gomes Pinto (Org.) Justiça Restaurativa: coletânea de artigos. Brasília, DF: Ministério da Justiça e PNUD, 2005. p. 163-187.

LAWRENZ, T. D.; RAVA, P. G. S. Percepção de diretores de escolas públicas sobre justiça restaurativa. Saúde mental em foco do CESUCA,1(1), 1-35, 2012. Disponível em:<http://ojs.cesuca.edu.br/index.php/saudementalemfoco/article/view/24>. Acesso em: 14 janeiro. 2013.

MAIOCHI, N. F.; MAIOCHI, R. Justiça restaurativa e educação. Revista de Estudos de Gestão, Jurídicos e Financeiros, 5, 148-187, 2015.

NUNES, A.O. Como restaurar a paz nas escolas: um guia para educadores. São Paulo: Contexo, 2011.

ORSINI, A.G.S.; LARA, C. A. S.Dez anos de práticas restaurativas no Brasil: a afirmação da justiça restaurativa como política pública de resolução de conflitos e acesso à justiça. Responsabilidades, 2(2), 305-324, 2012. Disponível em:<http://www8.tjmg.jus.br/presidencia/programanovosrumos/pai_pj/revista/edicao_02_02/08_Re Acesso em: 02 maio 2013.

PENIDO, E. A. ?Justiça e Educação: parceria para a cidadania? em Heliópolis/SP: a imprescindibilidade entre Justiça Restaurativa e Educação, 2009.Disponível em:<http://www.tjsp.jus.br/Download/CoordenadorialnfanciaJuventude/Pdf/JusticaRestaurativa/Artic IOB.pdf>. Acesso em: 02 maio. 2013.

PINHO, R. G. Justiça Restaurativa: um novo conceito. Revista Eletrônica de Direito Processual - REDP, 3(3), 242-268, 2009. Disponível em:<http://www.epublicacoes.uerj.br/index.php/redp/article/view/22177/16025. Acesso em 02 maio. 2013.

Poletto, k.;Poletto, M. Mediação de conflitos no contexto escolar. In M. Poletto, A. M. L. 
Souza, \& S. H. Koller (Orgs.).Direitos humanos, prevenção à violência contra crianças e adolescentes e mediação de conflitos: manual de capacitação para educadores. Porto Alegre: IDEOGRAF, 2013.p.230-236.

RISTUM, M.Violência na Escola, da Escola e contra a Escola. In S. G. Assis, P. Constantino, \& J. Q. Avanci (Orgs.). Impactos da violência na escola: um diálogo com professores. Rio de Janeiro: Ministério da Educação/FIOCRUZ, 2010.p. 65-94.

Sampaio, F. G. G, \& Almeida, D.S.O. Violência social e educacional: Uma Reflexão. Serviço Social \& Realidade, 17, 356-372, 2008.

Secretaria da Educação. (2009). Manual de proteção Escolar e promoção da cidadania: Sistema de proteção escolar. São Paulo: Secretaria da Educação/Fundação para Desenvolvimento da Educação.

Souza, A. M. L.; Poletto, M.;Koller, S. H. Apresentação. In M. Poletto, A. M. L. Souza, \& S. H. Koller (Org.). Direitos humanos, prevenção à violência contra crianças e adolescentes e mediação de conflitos: manual de capacitação para educadores. Porto Alegre: Ideograf, 2013.p. 7-10.

TERRE DES HOMMES LAUSANNE NO BRASIL. Prevenindo a violência e promovendo a justiça juvenil restaurativas: justiça juvenil restaurativa e práticas de solução positiva de conflitos. Fortaleza: Terre de hommes, 2013.

Trassi, M. L.; Malvasi, P. A. Violentamente pacíficos: descontruindo a associação entre juventude e violência. São Paulo: Cortez, 2010.

ZEHR, H. Trocando as lentes: um novo foco sobre o crime e a justiça (Trad. T. V. Acker). São Paulo: Palas Athena, 2008.

ZEHR, H.Justiça Restaurativa: teoria e prática (Trad. T. V. Acker). São Paulo: Palas Athena, 2012. 